\title{
The role of the robot-assisted procedure during total pancreatectomy: a viewpoint
}

\author{
Matteo De Pastena, Alessandro Esposito, Roberto Salvia \\ General and Pancreatic Surgery Unit, Pancreas Institute, University of Verona, Verona, Italy \\ Correspondence to: Roberto Salvia, MD, PhD. General and Pancreatic Surgery Unit, Pancreas Institute, University of Verona, Verona, Italy. \\ Email: roberto.salvia@univr.it. \\ Comment on: Weng Y, Chen M, Gemenetzis G, et al. Robotic-assisted versus open total pancreatectomy: a propensity score-matched study. \\ Hepatobiliary Surg Nutr 2020;9:759-70.
}

Submitted Feb 24, 2021. Accepted for publication Mar 11, 2021.

doi: $10.21037 / \mathrm{hbsn}-21-83$

View this article at: http://dx.doi.org/10.21037/hbsn-21-83

We read with great interest the article published in HepatoBiliary Surgery and Nutrition, "Robotic-assisted versus open total pancreatectomy: a propensity score-matched study" (1). Total pancreatectomy (TP) is a complex procedure, primarily performed for diseases involving the entire pancreas, which is increasing its diffusion due to a wide range of pancreatic diseases, including main duct intraductal papillary mucinous neoplasms, pancreatic ductal adenocarcinoma, multifocal pancreatic neuroendocrine tumors, chronic pancreatitis, multifocal metastatic pancreatic tumors, and completion pancreatectomy. However, there is still an unwillingness to do TP because of high postoperative morbidity and mortality.

A retrospective monocenter analysis was performed to investigate the safety and efficacy of robotic-assisted total pancreatectomy (RTP) compared to conventional open total pancreatectomy (OTP). A propensity score matching method was utilized to compare the RTP and OTP cohorts to minimize bias. Overall, 117 patients were eligible for the study. After the propensity score matching, two homogenous groups of 15 patients each were analyzed. The study results showed that major 30-day morbidity (Clavien-Dindo > IIIa) and 90-day mortality were similar between the two groups. After a median follow-up time of 15 (IQR, 8-24) months, both the RTP and OTP cohorts had a comparable quality of life regarding exocrine and endocrine insufficiency.

Some considerations can be made. The diffusion of minimally-invasive techniques for pancreatic resections has been significantly increasing. Several studies and reviews confirmed the efficacy and safety of the minimally-invasive approach particularly for resectioning benign and uncertain behavior pancreatic lesions (2). Few data are available on the use of the minimally-invasive approach in TP. Furthermore, the adoption of both laparoscopic and robotic procedures is reduced by the conflicting data on major morbidity and inhospital mortality after TP. Recently, a systematic review reported that overall morbidity ranged from $36 \%$ to $69 \%$ and mortality from $0 \%$ to $27 \%$ (3). However, these data are influenced by the expertise of the center. It has been widely reported that the short and long-term outcomes of the TP are influenced by the annual center volume for pancreatoduodenectomy and intraoperative estimated blood loss (4). The use of the robotic technique for TP could improve the procedure's surgical outcome (e.g., estimated blood loss). However, at the same time, RTP should be performed by expert surgeons at the end of their learning curve (open, laparoscopy and, only at the end, robotic pancreatic surgery).

The present manuscript/commentary does not include any evaluation relating the timing of the learning curve in pancreatic surgery and, finally, how to teach this surgery to the future generations, an unsolved problem at this time. In particulare se la disponibilità del robot rimarrà quella odierna che nella maggior parte dei casi vuol dire "quando non lo usa l'urologo".

It has been widely demonstrated that the robotic platform has several benefits during the resection, such as $3 \mathrm{D}$ vision, improved stability, muscle tremor filters, six axes of freedom, and a 360-degree range of articulation. These benefits could be relevant during accurate dissections, such as spleen-preserving pancreatectomies (5). Considering the indication to TP, the preservation of the spleen should continuously be taking in account and the use of the robot 
could improve the technique and results. Indeed, the spleen's immunological role and the significant reports of postoperative infectious complications related to its resection have led the surgeons to be more conservative in the surgical approach during TP, when feasible.

The economic impact of robotic surgery's adoption is one of the grey areas of the topic. Indeed, it is logical to assume that better clinical outcomes are associated with a reduction in costs, whereas the costs of the application of robotic surgery are high. As a result, an intense debate is ongoing on the robotic procedure's cost-effectiveness with still controversial results (6). However, improved quality of life (QoL) and cosmetic satisfaction are often mentioned to benefit minimally invasive surgery. After TP, the QoL has recognized to be inferior compared to the other pancreatic resections, reducing its indications (7).

Furthermore, establishing an apancreatic state and the consequent intestinal malabsorption and brittle diabetes have a significant impact on a patient's QoL. A simultaneous islet-cell autotransplantation was introduced during TP to overcome these relevant problems. This technique has been widely reported and is increasing its use to introduce robotassisted procedures, as Weng et al. (1) reported. The robotic approach introduced potential advantages, such as late blood supply preservation and optimization of the isolated islet cell population.

Considering the widespread of the robotic approach and the increased indication to TP, we believe that this topic should be deeply investigated with a multicenter randomized controlled trial to assess the safety and feasibility of the RTP definitively.

\section{Acknowledgments}

Funding: None.

\section{Footnote}

Provenance and Peer Review: This article was commissioned by the editorial office of Hepatobiliary Surgery and Nutrition. The article did not undergo external peer review.

Conflicts of Interest: All authors have completed the ICMJE uniform disclosure form (available at https://hbsn. amegroups.com/article/view/10.21037/hbsn-21-83/coif). The authors have no conflicts of interest to declare.

Ethical Statement: The authors are accountable for all aspects of the work in ensuring that questions related to the accuracy or integrity of any part of the work are appropriately investigated and resolved.

Open Access Statement: This is an Open Access article distributed in accordance with the Creative Commons Attribution-NonCommercial-NoDerivs 4.0 International License (CC BY-NC-ND 4.0), which permits the noncommercial replication and distribution of the article with the strict proviso that no changes or edits are made and the original work is properly cited (including links to both the formal publication through the relevant DOI and the license). See: https://creativecommons.org/licenses/by-nc-nd/4.0/.

\section{References}

1. Weng Y, Chen M, Gemenetzis G, et al. Robotic-assisted versus open total pancreatectomy: a propensity scorematched study. Hepatobiliary Surg Nutr 2020;9:759-70.

2. Esposito A, Balduzzi A, De Pastena M, et al. Minimally invasive surgery for pancreatic cancer. Expert Rev Anticancer Ther 2019;19:947-58.

3. Petrucciani N, Nigri G, Giannini G, et al. Total Pancreatectomy for Pancreatic Carcinoma: When, Why, and What Are the Outcomes? Results of a Systematic Review. Pancreas 2020;49:175-80.

4. Latenstein AEJ, Scholten L, Al-Saffar HA, et al. Clinical Outcomes after Total Pancreatectomy: A Prospective Multicenter Pan-European Snapshot Study. Ann Surg 2020. [Epub ahead of print]. doi:10.1097/ SLA.0000000000004551.

5. Esposito A, Casetti L, De Pastena M, et al. Robotic spleenpreserving distal pancreatectomy: the Verona experience. Updates Surg 2020. [Epub ahead of print]. doi: 10.1007/ s13304-020-00731-8.

6. De Pastena M, Esposito A, Paiella S, et al. Costeffectiveness and quality of life analysis of laparoscopic and robotic distal pancreatectomy: a propensity score-matched study. Surg Endosc 2021;35:1420-8.

7. Pulvirenti A, Pea A, Rezaee N, et al. Perioperative outcomes and long-term quality of life after total pancreatectomy. Br J Surg 2019;106:1819-28.

Cite this article as: De Pastena M, Esposito A, Salvia $\mathrm{R}$. The role of the robot-assisted procedure during total pancreatectomy: a viewpoint. HepatoBiliary Surg Nutr 2021;10(3):405-406. doi: 10.21037/hbsn-21-83 